\title{
Desafios da Qualificação no Brasil: Demandas dos Setores Tradicionais e Tecnológicos de Curto e Longo Prazo por Mão-de-obra Qualificada*
}

Joilson Dias ${ }^{1}$

Resumo: O objetivo deste trabalho é o de estimar as demandas setoriais, incluindo as dos setores tecnológicos, por mão-de-obra qualificada e menos qualificada, dos estados brasileiros. O modelo dinâmico empírico especificado foi baseado em Sargent (1978) que pressupõe a escolha entre pessoas qualificadas (acima de 11 anos de escolaridade) e menos qualificadas ( 11 anos ou menos de escolaridade). $O$ fator determinante da escolha é o custo entre esses capitais representado no modelo pelo coeficiente do custo de ajustamento. As estimativas em painel dinâmico para os dados dos estados no período 2002-2009 para o capital humano qualificado resultaram no seguinte: i) as demandas nos setores tradicionais (comércio, indústria e serviços) demonstraram que a principal fonte de crescimento vem do PIB dos setores; ii) $\mathrm{O}$ setor de serviços é o único que sofre influência negativa de aumentos salariais; iii) $\mathrm{O}$ custo de ajustamento demonstrou ser baixo nesses setores ou insignificantes. As demandas dos setores de alta tecnologia (indústria e serviços) possuem comportamentos diversos: i) na indústria o fator preponderante é a demanda por capital humano menos qualificado. Um aumento de $10 \%$ na mesma leva a um aumento na demanda por capital humano qualificado em 4,2\% em média, portanto os fatores são complementares; ii) no setor de serviços de alta tecnologia o fator predominante é o custo de ajustamento que foi bastante elevado $(\lambda=0,80)$, indicando que os custos de contratação são mais elevados neste setor comparados aos setores tradicionais. A demanda por capital humano menos qualificado tem como destaque o alto custo de ajustamento que supera o capital humano qualificado em todos os setores, exceto

\footnotetext{
* Esse paper foi financiado com recursos do Fundo de Estruturação de Projetos (FEP) do Banco Nacional de Desenvolvimento Econômico e Social (BNDES). Por meio desse fundo o BNDES financia, na modalidade não-reembolsável, a execução de pesquisas científicas, sempre consoante ao seu objetivo de fomento a projetos de pesquisa voltados para a ampliação do conhecimento científico sobre o processo de desenvolvimento econômico e social. Para maiores informações sobre essa modalidade de financiamento, acesse o site: http:// www.bndes.gov.br/SiteBNDES/bndes/bndes_pt/Institucional/Apoio_Financeiro/Programas_e_Fundos/fep. html. O conteúdo do paper é de exclusiva responsabilidade do(s) autore(s), não refletindo necessariamente, a opinião do BNDES e/ou da ANPEC.

1 Departamento de Economia - Universidade Estadual de Maringá - Maringá-PR. E-mail: jdias@uem.br.
} 
nos serviços de alta tecnologia. Isto significa que é mais dispendioso no curto e longo prazo a contratação de pessoas menos qualificadas do que qualificadas nos setores a exceção do setor de serviços de alta tecnologia. Estes resultados também apontam para a necessidade premente de qualificação de pessoas com escolaridade de até segundo grau (11 anos de escolaridade) para os setores em geral e de pessoas com educação em nível superior, especificamente voltadas para os setores de serviços de alta tecnologia no curto e longo prazo.

Palavras-chave: Desafios da qualificação; capital humano; custos de ajustamentos; painel dinâmicos.

JEL: C33, J3, J23, J24.

\title{
Challenges for Qualifying Works in Brazil: The Traditional and Technological Sectors Demand in the Short and Long Run for Human Capital
}

\begin{abstract}
The objective of this paper is to estimate sectorial demand - including the technological sector - for qualified and less human capital for the Brazilian states. The theoretical model used is based on Sargent (1978) where the choice can be made between hiring qualified worker (more than 11 years of education) versus non-qualified worker (11 years or less of education). The relative cost between the human capitals appears in the adjustment cost coefficient. The panel dynamic estimates for the period 2002-2009 data resulted in the following for qualified human capital: i) the demand in the traditional sectors (commerce, industry and service) showed that the main source of growth to be the sector's output growth; ii) the service sector is the only one to have dependency on the level of real wages, a negative coefficient elasticity; iii) the adjustment cost showed to be very low in the traditional sector. The technological sectors' demand behaves differently. The industrial technological sector demand for qualified human capital depends upon the demand for less qualified human capital, their cross elasticity is positive. An increase of $10 \%$ in the demand for less qualified human capital led an increase of 4.2\% in qualified human capital; therefore they are complementary to each other. In the technological service sector the most important aspect is the adjustment cost which was very high $(\lambda=0.80)$, therefore hiring qualified human capital is higher compared to less qualified worker in this sector. The demand for less qualified human capital has as main aspect the adjustment cost that is higher than the qualified human capital in every sector, except the technological service sector. These results indicate the need for an urgent policy that better qualifies workers with 11 years or less of education for most of the sectors and workers with tertiary education specifically for the technological service sector in the short and long run.
\end{abstract}

Keywords: Workers qualifying challenges; human capital; adjustment costs; dynamic panel.

JEL: C33, J3, J23, J24. 


\section{Introdução}

A formação de capital humano qualificado na economia está associado a uma política educacional em nível superior, ou seja, aquelas com mais de 11 anos de escolaridade. Neste caso, são considerados como indivíduos qualificados os que frequentam o nível superior ou tenham concluído o mesmo, bem como todos aqueles que estiverem frequentando ou concluído os cursos de especialização, mestrado e doutorado. Esta distinção da mão-de-obra frequentando o nível superior é compreensível, pois os ensinamentos no terceiro grau levam os indivíduos a adquirirem conhecimentos específicos de uma profissão. Já primeiro e segundo graus em geral tendem a transmitir conhecimentos generalizados das ciências, com exceção dos cursos técnicos.

Como consequência deste conhecimento mais específico e profissionalizado se observa um crescimento da demanda por pessoas qualificadas e uma redução na demanda por pessoas menos qualificada, conforme observado por Dias (2014). Usando dados da PNAD-Pesquisa de Amostra Domiciliar ${ }^{1}$ entre 1997 e 2009, o autor verificou que o crescimento da demanda por pessoas qualificadas subiu de uma média de $8,7 \%$ para $15,9 \%$ no período, enquanto que as pessoas menos qualificadas (11 anos ou menos de estudos) ocupavam $77,3 \%$ dos postos de trabalhos em 1997, sua participação reduziu para $76,4 \%$ em 2009, depois de ter um pico em 2002 de 77,9\%. Portanto, estes dados demonstram o crescimento de ocupações com conhecimento em nível superior em detrimento das ocupações que requerem conhecimentos de segundo grau ou inferior.

Outro aspecto importante é o crescimento da demanda em setores considerados tecnológicos. Por exemplo, o setor de tecnologia da informação e da comunicação (TIC) cresceu 18,3\% entre 2003 e 2006, no entanto sua demanda por pessoas qualificadas aumentou $40,7 \%{ }^{2}$ Como resultado este setor empregava 478.440 em 2003 e aumentou para 673.024 em 2006. Desta forma, este crescimento acelerado projeta um déficit para o setor de 72.000 profissionais qualificados para 2011 e 92.000 para $2013 .{ }^{3}$

A pergunta em aberto é a seguinte: Quais setores (ou setor) estariam contribuindo para uma expansão acentuada na demanda por pessoas qualificadas? Quais as características desta demanda? Para os setores os custos de ajustamento associados a contratação é maior para o capital humano menos qualificado ou qualificado? Neste artigo a preocupação central está em aprender quais os fatores determinantes da demanda nos setores econômicos dos estados.

1 Os dados da PNAD se encontram disponíveis no sítio do IBGE-Instituto Brasileiro de Geografia e Estatística: http://www.ibge.gov.br/home/estatistica/populacao/trabalhoerendimento/pnad2012/microdados.shtm. Acesso em fevereiro de 2013.

2 Veja Pesquisa Anual de Serviços 2003-2006, www.ibge.org.br. Acesso em fevereiro de 2013.

3 Veja resultado da pesquisa da Brasscom (Associação Brasileira de Empresas de Tecnologia da Informação e Comunicação) em www.brasscom.org.br. Acesso em fevereiro de 2013. 
O modelo teórico a ser utilizado tem como principal característica a decisão entre contratar pessoas qualificadas (acima de 11 anos de escolaridade) e/ou menos qualificadas (11 anos ou menos de escolaridade). $O$ fator determinante desta contratação está no coeficiente de ajustamento, quanto mais próximo de um, e quão maior for este coeficiente mais elevado será o custo de contratação deste capital humano. Assim, se o custo maior for o de contratar capital humano qualificado este coeficiente será maior neste setor do que o do capital humano menos qualificado. Como estes custos estão associados a outros fatores que não sejam os salários, por exemplo, despesas de contratação, qualificação da mão-de-obra, de demissão, etc., então para as empresas dos estados seria necessário políticas que minimizem estes custos.

Outro aspecto importante do modelo é que os preços relativos dos insumos (capitais humanos) entram nas equações de estimativas. As elasticidades dos salários e cruzadas indicam se a demanda do capital humano depende de seu próprio salário e/ou de salários em outros setores. Somado a este aspecto temos que a demanda de um tipo de capital humano pode depender da demanda de outro. Se elasticidade cruzada de demanda for positiva indica que estes capitais são complementares e se negativo substitutos.

O crescimento econômico do setor e/ou de outros setores podem influenciar a demanda por capital humano, quer seja este qualificado ou menos qualificado. Desta forma o modelo permite obter as elasticidades do produto e aprender sobre suas contribuições. Se for insignificante indica que o produto não exerce influência na demanda, mas se significante e elástica por exemplo pode ser um dos fatores determinantes do crescimento da demanda no curto e longo prazo.

A vantagem de se estudar esta demanda de forma dinâmica para setores e em nível de estados está associada aos seguintes aspectos: a) se estiver ocorrendo demanda por mão-de-obra qualificada em um setor maior que em outro, isto irá refletir em elasticidades de curto e longo prazo do produto e dos salários maiores para aquele setor do que para os demais. Estes resultados das elasticidades e do custo de ajustamento sinalizam que o setor ou setores demandam algum tipo de capital humano que não é facilmente encontrado no mercado, ou seja, pode estar havendo falta de mão-de-obra de uma qualificação específica para este setor. Neste caso, deve-se adotar uma política mais específica de formação de especialidades voltada para atender o referido setor; b) também permite aprender sobre o efeito substituição cruzado, ou seja, se está havendo um processo de substituição entre pessoas qualificadas e menos qualificadas nos diversos setores da economia dos estados. Se estiver ocorrendo esta substituição devemos obter elasticidades cruzada das qualificações e dos salários negativas que permitem verificar a direção da substituição.

É importante ressaltar que o custo de ajustamento nestes modelos reflete também a existência de custos associados às leis trabalhistas, bem como, a falta de oferta ou a necessidade de programas de remuneração ou treinamento diferenciados para contratação de pessoas qualificadas ou menos qualifica- 
das. Portanto, os modelos dinâmicos com custo de ajustamento, que estamos propondo, captam estes efeitos. Estes modelos permitem ainda que saibamos se os custos associados com a contratação de mão-de-obra qualificada são superiores ou inferiores aos dos menos qualificados nos diversos setores da economia.

A importância da compreensão dos custos de ajustamentos foi enfatizado por Hamermesh e Pfann (1996). Em nível internacional, segundo os autores, ocorre o seguinte: 1) os custos de ajustamento em geral são muito altos e podem chegar ao equivalente a um ano de pagamento em algumas indústrias; 2) a média dos custos de ajustamento aumenta com o aumento da qualificação dos trabalhadores, ou seja, os custos de ajustamento são baixos em setores que usam trabalhadores de baixa qualificação, mas extremamente elevados em setores que usam pessoas altamente qualificadas; 3 ) o custo de contratar normalmente excede o custo de promover pessoas qualificadas. ${ }^{4}$

Em resumo, além dos objetivos acima, este trabalho ainda se preocupa com elementos mais técnicos ao utilizar o sistema de Método de Momentos Generalizados (GMM-SYS) proposto por Arellano e Bond (1991), Arellano e Bover (1995), Blundell e Bond (1998) e as correções para amostra finita de Windmeijer (2005). As técnicas propostas pelos autores minimizam problemas de: a) regressão espúria; b) variáveis omitidas; e c) efeitos fixos dos estados. Assim, o emprego das técnicas propostas permite obter estimativas dinâmicas mais eficientes para os parâmetros desejados.

\section{Revisão bibliográfica}

Uma revisão detalhada de estudos dinâmicos sobre a demanda por emprego foi realizado por Dias (2014). Segundo o autor a literatura mais recente pode ser subdividida em dois grupos. A subdivisão proposta engloba somente os modelos dinâmicos. Se considerarmos os modelos estáticos temos na realidade três grupos: i) estimativas de elasticidades de curto prazo; ii) os efeitos decorrentes de políticas econômicas da substituição em nível micro de pessoas menos qualificadas por qualificadas; iii) os custos das políticas econômicas e mudanças estruturais - custos de ajustamentos - sobre o emprego no curto e longo prazo.

Os estudos realizados por Chahad e Luque (1989) e Pereira et alii (1989) foram os primeiros a obter as elasticidades de emprego devido as alterações no produto da economia. Estas elasticidades eram estáticas e somente do setor industrial. Os estudos das estimativas da elasticidade evoluíram para setoriais com os trabalhos de Meyer (1998), Pereira (1998), Pereira e Gonzaga

4 Hamermesh e Pfann (1996, p.1268). 
(1998). Estes autores utilizaram séries temporais em suas estimativas. As estimativas em geral da elasticidade emprego devido ao produto setorial se situam próximos de 0,95 e a dos salários -0,026, sendo que esta última não demonstrou ser significante.

O segundo grupo contém trabalhos, cuja característica principal é avaliar os efeitos da política econômica, especialmente a abertura comercial e seus efeitos sobre a substituição de pessoas menos qualificadas por qualificadas. Por exemplo, o trabalho de Fernandes e Meneses-Filho (2002). Os autores dividiram os trabalhadores da seguinte forma: a) qualificados (12 ou mais anos de estudos), b) intermediários (5 a 11 anos de estudos) e c) não qualificados ( o a 4 anos de estudos) para os dados das décadas de 80 e 90. A conclusão dos autores é que o crescimento dos setores exportadores e importadores influenciou a demanda por pessoas com conhecimento intermediário ( 5 a 11 anos de estudos). Estes substituíram especialmente os menos qualificados. Segundo o autor a parcela de trabalhadores intermediários alocados em tarefas simples em substituição aos não qualificados subiu de 15\% em 1981 para $47 \%$ em 1999.

Os autores Meneses-Filho e Rodrigues Jr. (2003) efetuaram o estudo dos efeitos da abertura comercial para as décadas de 80 e 90 sobre a demanda por trabalhadores qualificados, mas agora com 11 anos ou mais de estudos. Restringindo-se ao setor industrial brasileiro e usando os dados da PNAD 1981 a 1997, os autores encontraram um forte aumento na demanda por pessoas qualificadas no setor industrial brasileiro pós-abertura comercial. Segundo os mesmos em 1981 os indivíduos qualificados representavam 16,34\% dos empregos; já em 1999 estes ocupavam 27,09\% das funções. A explicação oferecida pelos autores foi de que a substituição decorreu da importação de produtos tecnológicos, máquinas e equipamentos com intensidade tecnológica e em especial computadores.

Usando dados da indústria e comparando o ano de 1987 com o ano 1998, portanto, em nível microeconômico, Abarche e Corsueil (2004) avaliaram se a abertura comercial levou a mudanças estruturais no emprego das indústrias. A conclusão foi de que as mudanças ocorridas não foram significantes a ponto de alterar a estrutura de emprego e salarial no setor industrial como um todo, quando se comparou o antes e após a abertura comercial. As mudanças ocorridas foram provavelmente entre as qualificações e dentro dos setores.

A confirmação da ocorrência de substituição entre as qualificações também foi obtida por Giovanetti e Menezes-filho (2006). A queda nas tarifas de importação de máquinas e equipamentos, especialmente os que demandam mão-de-obra qualificadas no período pós-abertura comercial foi a grande responsável pela substituição de pessoas menos qualificadas por pessoas qualificadas no período, segundo os autores.

Ribeiro e Jacinto (2008) propuseram uma medida mais específica de substituição entre os trabalhadores qualificados e não qualificados no setor 
industrial. Estes usaram as bases de dados RAIS, PIA e PINTEC/IBGE par ao período 1996-2003. As estimativas das elasticidades cruzadas entre os trabalhadores qualificados (12 anos ou mais de estudos), intermediários (8 e 11 anos de estudos) e não qualificados (o a 7 anos de estudos) confirmaram a maior demanda por pessoas qualificadas vis a vis as não qualificadas no setor industrial foram as seguintes: emprego 0,094 e salários -0,478. Portanto, um aumento de $10 \%$ nos salários dos trabalhadores intermediários gera um aumento de $0,94 \%$ de demanda por trabalhadores altamente qualificados e uma queda de 4,78\% no emprego dos trabalhadores intermediários, devido à elasticidade salarial cruzada. Para os autores as causas dessas substituições foram: i) abertura econômica; ii) os choques tecnológicos; e especialmente a iii) maior oferta de pessoas qualificadas. Este último manteve os salários reais das pessoas qualificadas relativamente estáveis incentivando sua contratação em detrimento dos demais.

O terceiro grupo engloba os modelos dinâmicos que consideram os custos de ajustamentos. Os dois primeiros trabalhos Gonzaga e Corsueil (2001) e Barros e Corsueil (2004) procuram obter coeficientes do custo de ajustamento no tempo do setor industrial e verificar se o mesmo se altera com os efeitos das políticas econômicas. O efeito de um aumento desses custos seria um recrudescimento na contratação de mão-de-obra em geral na indústria.

Os resultados de Gonzaga e Corsueil (2001) foram os seguintes: i) o coeficiente dos custos de ajustamentos obtido foi $\lambda=\lambda_{1}+\lambda_{2}=0,968$; ii) as elasticidade do produto de curto e longo prazo foram $\gamma=0,037$ e $\theta=\gamma /(1-\lambda)=1,13$, respectivamente; iii) e as elasticidade de curto e longo prazo do salário foram $\omega=-0,021$ e $\delta=\omega /(1-\lambda)=-0,66$, respectivamente. O resultado do custo de ajustamento do emprego são bastante elevados e muito próximos de 1 caracterizando uma alta influência de custos institucionais e não institucionais que faz com que o ajuste de emprego seja lento e gradual no tempo. Os testes de mudanças estruturais neste parâmetro indicaram evidências ainda que fracas de alteração no parâmetro nos anos de 1990 e 1995, portanto, pós-abertura comercial e a nova constituição de 1988 e posteriormente da estabilização da economia. No entanto, os diversos testes não foram conclusivos o suficiente para indicar uma alteração nos valores do parâmetro. A elasticidade salarial de longo prazo é alta, -o,66, ainda que seja inelástica, a mesma indica que aumentos salariais reais seriam penalizados com menor contratação de pessoas no longo prazo, portanto a interação entre oferta e demanda dependeria dos salários reais prevalentes no mercado.

Barros e Corsueil (2004) investigaram o impacto das mudanças introduzidas especificamente pela Constituição de 1988 na legislação trabalhista brasileira. A Constituição introduziu novos direitos trabalhistas como: 1) maior liberdade na organização sindical; 2) aumento dos valores das horas extras de 20\% para 50\%; 3) auxílio maternidade de 3 meses para 4 meses; 4) aumento de direito extra no pagamento de férias de 1/3. Os resultados das estimativas dos autores foram os seguintes: i) Coeficiente do custo de 
ajustamento $\lambda=0,5$; ii) As elasticidades de curto e longo prazo do produto não foram estimadas; iii) A elasticidade salarial de curto e longo prazo foram $\omega=-0,2$ e $\delta=\omega /(1-\lambda)=-0,40$.

O coeficiente de custo de ajustamento de $\lambda=0,5$ permaneceu estável ao longo do período, mesmo após as mudanças constitucionais. Os autores concluíram que as diversas regressões que explicariam potencialmente variações no coeficiente de ajustamento no período 1985-1997 não foram estatisticamente significantes.

Os dois trabalhos seguintes de Dias e Dias (2011) e Dias (2014) verificam se as políticas econômicas alteram ou não os coeficientes do custo de ajustamento em favor da contratação de pessoas qualificadas ou menos qualificadas. No primeiro trabalho o objetivo dos autores é compreender o papel exercido pelo aumento da demanda da classe média por pessoas qualificadas e menos qualificadas sobre o custo de ajustamento. No segundo artigo, o custo de ajustamento é estimado, mas considerando o papel do crescimento dos setores exportadores e importadores das economias dos estados. Usando estimativas em painel de dados dos estados brasileiros para o período 1997-2009, os autores estimaram em nível um modelo a partir do modelo de Sargent (1978) com custos quadráticos variáveis. A equação empírica derivada do modelo teórico foi a seguinte:

$$
\begin{aligned}
& l h_{1 q t}=a_{0}^{*}+\lambda l h_{1 q t-1}+a_{1}^{*} l y c_{q t}+a_{2}^{*} l y s_{q t}+a_{3}^{*} l y i_{q t}+a_{4}^{*} d w_{q t} \\
& a_{5}^{*} p c m_{q t}+a_{6}^{*} l h_{2 q t}+\xi_{t}
\end{aligned}
$$

Sendo que na equação, $q$ representa o estado; $t$ o tempo; $\alpha_{i}$, onde $i=0, \ldots, 5$ são os parâmetros a serem estimados; $l h_{1 q t}$ é a demanda por pessoas qualificadas com mais de 11 de escolaridade - pessoas cursando a universidade ou que a concluíram e ainda com especialização, mestrado e/ou doutorado; $l h_{2 q t}$ é a demanda por pessoas menos qualificadas com 11 anos ou menos de escolaridade (incluso os analfabetos); $y c, y s$ e $y i$ representam participação dos setores comércio, serviços e indústria no PIB do estado, respectivamente; $w$ representa a razão do salário capital humano no estado vis à vis o nacional; pcm representa o percentual de pessoas pertencentes a classe média nos estados; $\xi_{t}$ são os erros idiossincrático.

Os autores realizaram várias estimativas alternativas, onde o principal aspecto foi o de considerar diferentes especificações visando avaliar se as variáveis como salários, classe média e as produções setoriais poderiam ser endógenas ao sistema. A melhor especificação, onde os salários foram considerados endógenos, produziu os seguintes coeficientes de custo de ajustamento médio para capital humano qualificado $\lambda=0,28$ e 0,65 . Para as mesmas especificações, as estimativas para o capital humano menos qualificado resultaram em $\lambda=0,50$ e 0,83 . Neste caso seria mais dispendioso a contratação de capital humano menos qualificado na economia dos estados. A contribuição adicional dos autores para a literatura está associado a obtenção da elasticidade 
de demanda da classe média, cujo valores obtidos estiveram entre 6,7 e 8,4 para o curto prazo e de 22 para o longo prazo, portanto, bastante elevadas.

O trabalho mais recente de Dias (2014) explorou novamente a questão da demanda por pessoas qualificadas e menos qualificadas associadas aos setores exportadores e importadores das economias dos estados brasileiros. O autor usou dados de painel para estimar o modelo de Sargent (1978). Este modelo pressupõe a decisão entre contratar pessoas com as seguintes qualificações: a) com conhecimento fundamental (1 a 8 anos de estudos); b) com conhecimento intermediário (9 a 11 anos de estudos); c) e com conhecimento em nível superior (12 anos ou mais de estudos). As principais conclusões desse trabalho foram as seguintes:

1) O custo de contratação (ajustamento) do capital humano de nível superior é inferior aos demais, o que parece justificar sua maior demanda relativa;

2) As elasticidades cruzadas não significantes, o que parece indicar que não está ocorrendo substituição entre os diferentes grupos de escolaridade;

3) Existe complementariedade entre capital humano com educação intermediária e os demais, portanto, uma maior demanda relativa desse capital humano está associada a maior demanda dos demais;

4) As elasticidades salariais dos capitais humanos com educação fundamental e superior são positivas e elásticas no longo prazo, portanto, influenciam a demanda desses capitais no longo prazo, mas a do capital humano com educação intermediária que parece estar em falta;

5) A elasticidade do produto é positiva e elástica no longo prazo para o capital humano com educação em nível superior, o que indica o seu crescimento relativo aos demais no longo prazo.

Os resultados acima indicam a necessidade de políticas educacionais que fomentem a formação em segundo e terceiro graus. Em resumo, os modelos dinâmicos com custos de ajustamentos abordam os problemas de mudanças estruturais nas economias, especialmente os associados à abertura econômica, mudanças constitucionais e estabilização econômica. Os custos de ajustamento não apresentam estatísticas significantes para estas alterações estruturais ocorridas. Vale ressaltar que a abordagem para diferentes setores da economia inova em relação a esta literatura. Quanto às elasticidades de curto e longo prazo associadas a salários também são obtidas em nível agregado ou especificamente para o setor industrial, portanto falta na literatura estimativas setoriais, em especial os setores de alta tecnologia, que indiquem demandas mais específicas por capital humano qualificado ou menos qualificado. 


\section{Modelo Empírico Proposto}

O modelo preliminar a ser usado nas estimativas é derivado do modelo proposto por Sargent (1978). Os detalhes a adaptação do modelo para a realidade do Brasil se encontra em Dias (2014). De acordo com o autor podemos considerar as seguintes equações empíricas a partir do modelo de Sargent (1978):

$$
\begin{gathered}
l H_{1 q i, t}=\lambda l H_{1 q i, t-1}+\omega_{1 i} l w_{1 q i, t}+\omega_{2 i, 1} l w_{2 q i, t}+\gamma_{1 i} l y_{i t}+\varphi_{1 i} l H_{2 m q i, t}+\varepsilon_{1 q i, t} \\
l H_{2 m q i, t}=\mu l H_{2 m q i, t-1}+\omega_{2 i} l w_{1 m q i, t}+\omega_{1 i, 2} l w_{1 q i, t}+\gamma_{2 i} l y_{i t}+\varphi_{2 i} l H_{1 q i, t}+\varepsilon_{2 q i, t}
\end{gathered}
$$

Nas equações acima, o indicador do estado $j$ foi propositadamente deixado de ser especificado, uma vez que as estimativas consideram somente os setores econômicos dos estado. As variáveis estão escritas em logaritmo, sendo que $l H_{1 q i, t}$ representa o capital humano qualificado com escolaridade acima de 11 anos; $l H_{2 m q i, t}$ a demanda relativa de capital humano menos qualificado; salários reais em logaritmo dos setores por estado $\left(l w_{1 q i, t}\right)$ e $\left(l w_{2 m q i, t}\right)$ o produto $\left(y_{i t}\right)$ representa o produto em nível setorial dos estados. A estabilidade em torno do nível ótimo requer que as variações dos logaritmos sejam estáveis, representados pela estabilidade das seguintes elasticidades: intertemporais $(\lambda, \mu)$, do salário $\left(\omega_{1 i}, \omega_{2 i}\right)$, cruzadas dos salários $\left(\omega_{2 i, 1}, \omega_{1 i, 2}\right)$, do produto dos setores $\left(\gamma_{1 i}, \gamma_{2 i}\right)$ e cruzada do capital humano $\left(\varphi_{1 i}, \varphi_{2 i}\right)$. Maiores detalhes dos dados e da técnica a ser empregada serão descrito na seção a seguir.

\section{Análise dos Dados e as Especificações Econométricas}

Os dados da demanda de capitais humanos por setor $i$ por estado $\left(H_{1 q i, t}\right)$ e ( $\left.H_{2 m q i, t}\right)$ e dos salários reais dos setores por estado $\left(w_{1 q i, t}\right)$ e $\left(w_{2 m q i, t}\right)$ têm como fonte a PNAD-Pesquisa Nacional por Amostra de Domicílios para o período 2002-2009. O uso dos dados a partir de 2002 se deveu a padronização utilizadas pela PNAD na classificação das atividades econômicas. A partir de 2002 o sistema de classificação obedeceu a CNAE-Classificação Nacional de Atividades Econômicas.

As definições de capitais humanos a serem utilizados serão as seguintes: 1) $\left(H_{1 q i, t}\right)$ é o capital humano qualificado representado pela quantidade de pessoas dos estados empregadas com os seguintes graus de escolaridade: i) frequentando nível superior; ii) nível superior completo; iii) pós-graduação incompleta e completa - incluso os que frequentam especialização, mestrado e doutorado; 2$)$ o capital humano menos qualificado $\left(H_{2 m q i, t}\right)$ é a quantidade de pessoas dos estados com primário incompleto, primário completo, secundário incompleto e secundário completo. É importante frisar que na definição de capital humano menos qualificado não foi considerado as pessoas analfabetas. O motivo para desconsiderar analfabetos é que o objetivo da sociedade 
é o de qualificar pessoas, portanto não faz sentido estimar demandas que considerem analfabetos.

Os setores de alta tecnologia correspondem aos seguintes códigos da CNAE: 1) Indústria de alta tecnologia - 210-Fabricação de celulose, papel e produtos de papel, 220-Edição, impressão e reprodução de gravações, 230-Fabricação coque, refino de petróleo, elaboração de combustíveis nucleares e produção de álcool, 240-Fabricação de produtos químicos, 250-Fabricação de artigos de borracha e plásticos, 290-Fabricação de Máquinas e Equipamentos, 300-Fabricação de máquinas para escritório e equipamentos de informática, 310-Fabricação de máquinas e aparelhos elétricos, 320-Fabricação de material eletrônico e de aparelhos de comunicações, 330-Fabricação de equipamentos de instrumentação médico-hospitalares, instrumentos de precisão e ópticos, equipamentos para automação industrial e outros, 340-Fabricação e montagem de veículos automotores, reboques e carrocerias e 350-Fabricação de outros equipamentos de transportes; 2) Serviços de alta tecnologia - 640-Correios e telecomunicações, 650-Intermediação financeira, exclusive de seguros e previdência privada, 660-Seguros e previdência privada, 670-Atividades auxiliares da intermediação financeira, 720-Atividades de informática e conexas, 730-Pesquisa e desenvolvimento das ciências, 740-Serviços prestados principalmente às empresas, 800-Educação e 920-Atividades recreativas, cultural e desportiva.

As definições das variáveis que aparecem na Tabela 1 são as variáveis descritas a seguir, mas com valores normais, enquanto que tabelas de estimativas, Tabelas 2-5, são as mesmas variáveis mas em logarítimos (precedidas de l): 1) $H_{1 q c o m, t}, H_{1 q i n d, t}, H_{1 q s e r v, t}, H_{1 q i a t, t}$ e $H_{1 q s a t, t}$ representam a quantidade de capital humano qualificado empregado nos estados (amostra PNAD) nos setores: comércio, indústria, serviços, indústria e serviços de alta tecnologia, respectivamente; 2) $H_{2 m q c o m, t}, H_{2 m q i n d, t}, H_{2 m q s e r v, t}, H_{2 m q i a t, t}$ e $H_{2 m q s a t, t}$ são as quantidades de capital humano menos qualificado empregados nos estados e nos seguintes setores (amostra PNAD): comércio, indústria, serviços, indústria e serviços de alta tecnologia; 3) $w_{1 q c o m, t}, w_{1 q i n d, t}, w_{1 q s e r v, t}, w_{1 q i a t, t}$ e $w_{1 q s a t, t}$ são os salários médios reais dos capitais humanos qualificados nos respectivos setores; 4) $w_{2 \text { mqcom }, t}$, $w_{2 m q i n d, t}, w_{2 m q s e r v, t}, w_{2 m q i a t, t}$ e $w_{2 m q s a t, t}$ representam os salários reais médios dos capital humanos menos qualificados nos estados e respectivos setores; 5) $y_{\text {pibcom }, t}, y_{\text {pibind }, t}$ e $y_{\text {pibserv }, t}$ são os PIBs dos setores comércio, indústria e serviços dos estados, sendo que $y_{p i b, t}$ representa o PIB total dos estados incluindo os demais setores da economia.

Os salários reais $\left(w_{1 q i, t}, w_{2 m q i, t}\right)$ são uma média ponderada considerando cada nível educacional pelo seu respectivo salário real e por estado. A variável $\left(y^{*}\right)$ representa o PIB-Produto Interno Bruto real do setores. As variáveis reais estão a preços de 2000. As variáveis que representam os produtos dos setores e dos estados possuem como fonte o IPEA-Instituto de Pesquisa Econômica Aplicada (www.ipeadata.gov.br), sendo as demais fonte da PNAD-Pesquisa 
Nacional por Amostra de Domicílios (www.ibge.gov.br).

Na tabela abaixo a média da amostra PNAD de pessoas qualificadas com 11 anos ou mais no setor industrial é de 37.361, com um mínimo de 164 pessoas e um máximo de 458.027; no setor industrial de alta tecnologia esta amostra este valores são respectivamente 18.675, com um mínimo de 64 e um máximo de 335.882. Os salários médio real do setor industrial no período foi de $\mathrm{R} \$ 2.114,97$, com um mínimo de $\mathrm{R} \$ 460$,oo e o máximo de $\mathrm{R} \$ 5.488,66$; os salários médios do setor industrial de alta tecnologia foi de $\mathrm{R} \$ 2.181,18$, com o valor mínimo de $\mathrm{R} \$$ 640,00 e máximo de $\mathrm{R} \$ 10.543,28$.

A média das pessoas menos qualificadas no setor de serviços é de 232.048, com um mínimo nos estados e no período de 4.678 e máximo de 1.669.132; no setor de serviços de alta tecnologia temos que a média nos estados é de 220.644, mínimo de 12.283 e máxima 1.738.728. Os salários médios reais destes setores $\mathrm{R} \$ 397,39$ e R $\$ 477,32$, respectivamente; os valores mínimos são: $R$ \$ 162,32 e R \$ 139,89, com o valores máximos de $R$ \$ 659,95 e 2.37,30, respectivamente.

Os valores das variáveis que representam os PIBs estão em milhões de reais a preços de 2000. Portanto, o PIB real médio do comércio é R \$5.580,o milhões de reais, da indústria $\mathrm{R} \$ 12.500,0$ milhões de reais, serviços $\mathrm{R} \$ 29.100,0$ milhões reais e o total dos estados $\mathrm{R} \$ 51.700$,o milhões de reais.

Considerando que os dados são representados por uma amostra da PNAD, Tabela 1, portanto a descrição acima refere-se a proporção média desta amostra nos estados. A descrição será resumida aos setores de indústria e de indústria de alta tecnologia para o capital humano qualificado e do setor de serviços e serviços de alta tecnologia para o capital humano menos qualificado.

Considerando ainda que para o sistema de estimativas o importante são as variações das variáveis entre os estados e no tempo, optamos por usar os valores da amostra da PNAD em vez de converter para valores totais dos estados usando dados populacionais. Desta forma se evita introduzir alterações na distribuição das variáveis. 
TABELA 1 - DADOS DO MODELO: 2002 - 2009

\begin{tabular}{|c|c|c|c|c|c|c|c|}
\hline Variável & Média & Desv. Padrão & Mínimo & Máximo & $\mathrm{n}$ & $\mathrm{T}$ & $\mathrm{N}$ \\
\hline$H_{1 q c o m, t}$ & 53.525 & 91.850 & 184 & 589.983 & 27 & 8 & 216 \\
\hline$H_{1 q i n d, t}$ & $37 \cdot 361$ & 68.803 & 164 & 458.027 & 27 & 8 & 216 \\
\hline$H_{1 q s e r v, t}$ & 19.607 & 37.197 & 173 & 240.745 & 27 & 8 & 216 \\
\hline$H_{1 q i a t, t}$ & 18.675 & 54.632 & 64 & 335.882 & 27 & 8 & 216 \\
\hline$H_{1 q s a t, t}$ & 179.942 & 285.998 & 4.064 & 1.743 .066 & 27 & 8 & 216 \\
\hline$H_{2 m q c o m, t}$ & 456.873 & 562.353 & 12.007 & 2.965 .430 & 27 & 8 & 216 \\
\hline$H_{2 m q i n d, t}$ & 472.575 & 635.979 & $13 \cdot 477$ & $3 \cdot 340.732$ & 27 & 8 & 216 \\
\hline$H_{2 m q s e r v, t}$ & 232.048 & 314 & 4.678 & 1.669 .132 & 27 & 8 & 216 \\
\hline$H_{2 m q i a t, t}$ & 80.586 & 192.049 & 322 & 1.117 .162 & 27 & 8 & 216 \\
\hline$H_{2 m q s a t, t}$ & 220.644 & $305 \cdot 398$ & 12.283 & 1.738 .728 & 27 & 8 & 216 \\
\hline$W_{1 q c o m, t}$ & $\mathrm{R} \$ 1.513,27$ & $\mathrm{R} \$ 484,03$ & $\mathrm{R} \$ 321,27$ & $\mathrm{R} \$ 3.683,38$ & 27 & 8 & 216 \\
\hline$W_{1 q i n d, t}$ & $\mathrm{R} \$ 2.114,98$ & $\mathrm{R} \$ 794,34$ & $\mathrm{R} \$ 466,37$ & $\mathrm{R} \$ 5.488,66$ & 27 & 8 & 216 \\
\hline$W_{1 q s e r v, t}$ & $\mathrm{R} \$ 1.607,00$ & $\mathrm{R} \$ 737,10$ & $\mathrm{R} \$ 672,92$ & $\mathrm{R} \$ 5 \cdot 911,82$ & 27 & 8 & 216 \\
\hline$W_{1 q i a t, t}$ & $\mathrm{R} \$ 2.181,18$ & $\mathrm{R} \$ 1.044,58 \mathrm{I}$ & $\mathrm{R} \$ 640,00$ & $\mathrm{R} \$ 10.543,28$ & 27 & 8 & 216 \\
\hline$w_{1 q s a t, t}$ & $\mathrm{R} \$ 1.513,47$ & $\mathrm{R} \$ 465,62$ & $\mathrm{R} \$ 820,72$ & $\mathrm{R} \$ 3 \cdot 556,15$ & 27 & 8 & 216 \\
\hline$W_{2 m q c o m, t}$ & $\mathrm{R} \$ 372,27$ & $\mathrm{R} \$ 90,68$ & $\mathrm{R} \$ 204,93$ & $\mathrm{R} \$ 607,33$ & 27 & 8 & 216 \\
\hline$W_{2 m q i n d, t}$ & $\mathrm{R} \$ 335,95$ & $\mathrm{R} \$ 80,20$ & $\mathrm{R} \$ 154,50$ & $\mathrm{R} \$ 499,63$ & 27 & 8 & 216 \\
\hline $\mathcal{W}_{2 m q s e r v, t}$ & $\mathrm{R} \$ 397,39$ & $\mathrm{R} \$ 104,01$ & $\mathrm{R} \$ 162,32$ & $\mathrm{R} \$ 659,95$ & 27 & 8 & 216 \\
\hline$w_{2 m q i a t, t}$ & $\mathrm{R} \$ 456,20$ & $\mathrm{R} \$ 192,36$ & $\mathrm{R} \$ 105,14$ & $\mathrm{R} \$ 2.250,00$ & 27 & 8 & 216 \\
\hline $\mathcal{W}_{2 m q s a t, t}$ & $\mathrm{R} \$ 477,32$ & $\mathrm{R} \$ 195,91$ & $\mathrm{R} \$ 139,89$ & $\mathrm{R} \$ 2.37,29$ & 27 & 8 & 216 \\
\hline$y_{\text {pibcom }, t}$ & $\mathrm{R} \$ 5 \cdot 580,0$ & $\mathrm{R} \$ 9.540,0$ & $\mathrm{R} \$ 189,5$ & $\mathrm{R} \$ 58.300,0$ & 27 & 8 & 216 \\
\hline$y_{\text {pibind }, t}$ & $\mathrm{R} \$ 12.500,0$ & $\mathrm{R} \$ 2.360,0$ & $\mathrm{R} \$ 182,5$ & $\mathrm{R} \$ 128.000,0$ & 27 & 8 & 216 \\
\hline$y_{\text {pibserv }, t}$ & $\mathrm{R} \$ 29.100,0$ & $\mathrm{R} \$ 51.800, \mathrm{or}$ & $\mathrm{R} \$ 1.388, \mathrm{o}$ & $\mathrm{R} \$ 305.000,0$ & 27 & 8 & 216 \\
\hline$\underline{y_{p i b, t}}$ & $\mathrm{R} \$ 51.700, \mathrm{o}$ & $\mathrm{R} \$ 91.400, \mathrm{ooH}$ & $\mathrm{R} \$ 1.899,0$ & $\mathrm{R} \$ 524.000,0$ & 27 & 8 & 216 \\
\hline
\end{tabular}

Fonte: PNAD's 2002 - 2009 e www.ipeadata.gov.br. 


\section{Especificações e Estimativas dos Modelos Econométricos Dinâmicos}

As especificações dos modelos econométricos dinâmicos a serem apresentados nas tabelas a seguir foram decorrentes dos testes propostos por Breusch e Pagan (1980), Baltagi e Li (1991) e Baltagi e Li (1995) chamados de testes dos componentes dos erros. Também foram considerados os testes de heterocedasticidade proposto por Greene (2000) e o especificação baseado em Hausman (1978). A escolha das variáveis endógenas e exógenas foram consideradas com base nos testes de Wooldridge (2002), bem como os de autoregressividades de primeira e segunda ordem (AR(1) e AR(2)) e da qualidades dos instrumentos sugeridos por Sargan (1988).

Além dos testes acima foi empregado a técnica de estimativas dinâmicas das equações (2) e (3), denominada de GMM-SYS, desenvolvidos por Hsiao (1982), Arellano e Bond (1991), Arellano e Bover (1995), Blundell e Bond (1997) e Windmeijer (2005). Esta técnica permite estimar o conjunto de equações formada pelo nível e em diferenças de forma simultânea, assim os parâmetros obtidos não sofrem de viés devido a variáveis omitidas; além do que, as variáveis em níveis são instrumentos da equação em diferença e as variáveis em diferença são instrumentos das variáveis em níveis. Mais especificamente foram estimados os seguintes conjuntos para cada equação de demanda por capital humano qualificado e menos qualificado de cada setor:

$$
\begin{gathered}
H_{q i t}=H_{q i t-1} \alpha+x_{q i t} \beta+\eta_{q}+u_{q t} \\
H_{q i t}-H_{q i t-1}=\left(H_{q i t-1}-H_{q i t-2}\right) \alpha+\left(x_{q i t}-x_{q i t-1}\right) \beta+\left(u_{q t}-u_{q t-1}\right) \\
E\left[H_{q t-s}\left(u_{q t}-u_{q t-1}\right)\right]=0 \text { para } s \geq 2 ; t=3, \ldots, T \\
E\left[x_{q t-s}\left(u_{q t}-u_{q t-1}\right)\right]=0 \text { para } s \geq 2 ; t=3, \ldots, T \\
E\left[\left(H_{q t-s}-H_{q t-s-1}\right)\left(\eta_{q}+u_{q t}\right)\right]=0 \text { para } s=1 \\
E\left[\left(x_{q t-s}-x_{q t-s}\right)\left(\eta_{q}+u_{q t}\right)\right]=0 \text { para } s=1
\end{gathered}
$$

O conjunto de equações (4) - (9) será estimado pelo Método de Momentos Generalizados (GMM-SYS). As estimativas serão realizadas considerando diferentes especificações visando estabelecer exogeneidade das variáveis.

Nas tabelas da seção a seguir, as estimativas dinâmicas dos setores tradicionais e de alta tecnologia apresentam nas colunas impares estimativas que consideram a correção para pequenas amostras conforme sugerido por Windmeijer (2005). Assim, os desvios padrões calculados são robustos. Este método, no entanto, não permite que se calcule o teste de qualidade dos instrumentos proposto por Sargan (1988). Assim, optamos por apresentar nas colunas pares estimativas utilizando a técnica twostep que permite calcular o teste de Sargan (1988), neste caso os erros não são robustos para pequenas amostras, mas os testes de AR(1), AR(2) e Sargan são válidos. Na análise dos 
coeficientes somente serão considerados quando a variável apresenta significância em ambos os métodos, robusto e twostep. Devido a proximidade dos resultados dos coeficientes será analisado somente os coeficientes das estimativas em que se usou o método robusto.

\subsection{Demanda dos Setores Tradicionais}

\subsubsection{Capital Humano Qualificado}

Os setores do comércio, indústria e serviços, aqui denominados de tradicionais, demonstraram estarem muito mais associados com fatores que determinam o nível ótimo de longo prazo $\left(l H_{1 q i t}=f\left(l H_{1 q i}^{*}\right)\right)$ do que com o ajuste dinâmico no tempo associado com os custos de ajustamentos do emprego no tempo $\left(l H_{1 q i t}=\lambda l H_{1 t-1}\right)$.

De acordo com a Tabela 2, abaixo, o setor de comércio foi o único setor que apresentou o parâmetro que representa o custo de ajustamento $\left(\lambda=\lambda_{1}+\lambda_{2}+\lambda_{3}\right)$ sendo o $\lambda_{2}=0,265$. Este setor possui elasticidade salarial não significante, bem como seus salários não influenciam os demais setores em suas contratações de capital humano qualificado, pois $l w_{1 q c o m, t}$ não demonstrou ser significante em nenhum conjunto de regressões. A elasticidade de demanda do produto demonstrou ser significante para o PIB do comércio apesar de que inelástica, $l y_{\text {pibcom }, t}=0,58$. A elasticidade cruzada de demanda por capital humano menos qualificado $\left(l H_{2 m q c o m, t}\right)$ demonstrou não exercer influência na contratação de capital humano qualificado no comércio.

O setor industrial não apresenta significância nos parâmetros que compõem o custo de ajustamento $\left(\lambda=\lambda_{1}+\lambda_{2}+\lambda_{3}\right)$. A elasticidade salarial $\left(l w_{\text {lqind, }}=0,248\right)$, significante a $10 \%$, demonstrou ser positiva, ou seja, maiores salários levam a maiores contratações neste setor; este resultado indica que setor contrata mesmo sob aumentos salariais do capital humano qualificado.

A elasticidade de demanda do produto (PIB do setor) confirma a sua importância como elemento determinante no aumento da demanda por capital humano qualificado na indústria, $l y_{\text {pibind, }}=0,77 e 1,24$. Estes resultados de elasticidade obtidos pelas duas técnicas já descritas, indicam que a elasticidade pode ser igual ou maior do que um neste setor. No entanto, independente de serem ou não elásticas, os resutlados confirmam a preponderância do crescimento do produto no crescimento do emprego por capital humano no setor indústrial. 
TABELA 2 - COMÉRCIO, INDÚSTRIA E SERVIÇOS - CAPITAL HUMANO QUALIFICADO

\begin{tabular}{|c|c|c|c|c|c|c|}
\hline & \multicolumn{2}{|c|}{ Comércio } & \multicolumn{2}{|c|}{ Indústria } & \multicolumn{2}{|c|}{ Serviços } \\
\hline & $\begin{array}{c}\text { (1) } \\
l H_{1 q c o m, t}\end{array}$ & $\begin{array}{c}\text { (2) } \\
l H_{1 q c o m, t}\end{array}$ & $\begin{array}{c}\text { (3) } \\
l H_{1 \text { qind, } t}\end{array}$ & $\begin{array}{c}\text { (4) } \\
l H_{1 q i n d, t}\end{array}$ & $\begin{array}{c}(5) \\
l H_{1 q s e r v, t}\end{array}$ & $\begin{array}{c}\text { (6) } \\
l H_{1 q s e r v, t}\end{array}$ \\
\hline \multirow{2}{*}{$L . l H_{1 q i, t}$} & 0.0101 & 0.00397 & 0.0533 & 0.0859 & -0.183 & -0.0787 \\
\hline & [0.13] & [0.07] & {$[0.22]$} & [1.13] & {$[-1.30]$} & [-o.84] \\
\hline \multirow{2}{*}{$L 2 . l H_{1 q i, t}$} & $0.265^{* * *}$ & $0.281^{* * *}$ & -0.162 & $-0.153^{* * *}$ & -0.160 & -0.0953 \\
\hline & [3.10] & [5.97] & {$[-1.61]$} & {$[-2.61]$} & {$[-1.58]$} & {$[-1.25]$} \\
\hline \multirow{2}{*}{$L 3 . l H_{1 q i, t}$} & 0.0445 & 0.0461 & & & & \\
\hline & {$[0.50]$} & [1.08] & & & & \\
\hline \multirow{2}{*}{$l w_{1 q c o m, t}$} & 0.0131 & -0.0861 & -0.0227 & -0.0727 & -0.137 & $-0.108^{* *}$ \\
\hline & [0.10] & [-0.59] & [-0.12] & {$[-1.63]$} & {$[-1.04]$} & {$[-2.20]$} \\
\hline \multirow{2}{*}{$l w_{1 q i n d, t}$} & -0.0817 & -0.0412 & $0.248^{*}$ & $0.163^{*}$ & 0.0465 & $0.0894^{* *}$ \\
\hline & {$[-0.80]$} & {$[-1.19]$} & {$[1.73]$} & [1.71] & [0.42] & [2.15] \\
\hline \multirow{2}{*}{$l w_{1 q s e r v, t}$} & 0.0835 & $0.0803^{* *}$ & -0.0603 & $-0.0837^{* *}$ & $-0.428^{* * *}$ & $-0.531^{* * *}$ \\
\hline & {$[1.25]$} & [2.34] & {$[-0.63]$} & {$[-1.99]$} & {$[-2.60]$} & {$[-4.28]$} \\
\hline \multirow{2}{*}{$l y_{\text {pibcom }, t}$} & $0.580^{* * *}$ & $0.629^{* * *}$ & & & & \\
\hline & [2.81] & [4.50] & & & & \\
\hline \multirow{2}{*}{$l y_{\text {pibind }, t}$} & & & $0.775^{* * *}$ & $1.247^{* * *}$ & & \\
\hline & & & [2.96] & [3.93] & & \\
\hline \multirow{2}{*}{$l y_{\text {pibserv }, t}$} & & & & & $1.303^{* * *}$ & $1.376^{* * * *}$ \\
\hline & & & & & {$[3.14]$} & {$[2.81]$} \\
\hline \multirow{2}{*}{$l H_{2 m q c o m, t}$} & 0.125 & 0.0699 & & & & \\
\hline & [0.47] & [0.47] & & & & \\
\hline \multirow{2}{*}{$l H_{2 m q i n d, t}$} & & & $0.553^{* *}$ & 0.0627 & & \\
\hline & & & [1.97] & {$[0.24]$} & & \\
\hline \multirow[t]{2}{*}{$l H_{2 m q s e r v, t}$} & & & & & 0.277 & 0.0400 \\
\hline & & & & & {$[0.78]$} & [0.12] \\
\hline Constante & $-3.149^{*}$ & $-2.918^{* * *}$ & $-9.066^{* * * *}$ & $-9.534^{* * * *}$ & $-8.889^{* * *}$ & $-8.616^{* * *}$ \\
\hline $\begin{array}{l}\text { Dummies } \\
\text { ano }\end{array}$ & Sim & Sim & Sim & Sim & Sim & Sim \\
\hline Observações & 216 & 216 & 216 & 216 & 216 & 216 \\
\hline $\operatorname{AR}(1)$ & 0,026 & 0,033 & 0,008 & 0,143 & 0,006 & 0,042 \\
\hline $\operatorname{AR}(2)$ & 0,461 & 0,451 & 0,703 & 0,945 & 0,412 & 0,731 \\
\hline Sargan teste & - & 0,997 & - & 0,999 & - & 0,999 \\
\hline
\end{tabular}

Estatística de t entre parênteses.

Valores da significância: ${ }^{*} \mathrm{p}<0.10,{ }^{* *} \mathrm{p}<0.05,{ }^{* *} \mathrm{p}<0.01$ 
O setor de serviços não apresenta significância no parâmetro que representa o custo de ajustamento, $\left(\lambda=\lambda_{1}+\lambda_{2}+\lambda_{3}\right)$. As elasticidades que lograram ser significante foram a dos salários reais $\left(l w_{1 q s e r v, t}=-0,428\right)$ e do produto $\left(l y_{\text {pibserv }, t}=1,303\right)$. A elasticidade do produto demonstrou ser elástica $\mathrm{e}$ robusta para as especificações testadas. O valor acima de 1,3 indica a mesma como uma fonte importante de crescimento da demanda no setor de serviços. É importante frisar que aumentos salariais em termos reais levam a redução na demanda por capital humano qualificado neste setor.

A demanda por capital humano qualificado nos setores tradicionais está amplamente associada ao crescimento do produto do seu setor. Testes considerando a influência do PIB de outros setores não demonstraram ser significantes ou não passaram nos testes de autoregressidade e/ou de qualidade dos instrumentos, portanto deixamos de apresentar os mesmos. Estes setores parecem não sofrer com os custos de ajustamento, ou seja, de políticas que possam influenciar os custos de contratações do capital humano qualificado. A quantidade de demanda atual está associada a fatores que determinam o emprego ótimo de longo prazo, em especial o produto dos respectivos setores. Outro fator interessante é que a elasticidade cruzada dos salários entre os setores demonstraram não ser significantes, ou seja, o salário real de outros setores não é um fator que influencia as contratações de capital humano qualificado.

\subsubsection{Capital Humano Menos Qualificado}

A demanda por capital humano menos qualificado no setor comercial está associado somente a quantidade empregada no período anterior. O custo de ajustamento $\mu=\mu_{1}+\mu_{3}=0,76$ neste setor é elevado e indica que políticas econômicas que afetam os custos dos capitais humanos menos qualificado afetam as contratações neste setor. As elasticidades do produto e dos salários não são significantes, bem com a elasticidade cruzada do capital humano qualificado.

A demanda por capital humano menos qualificado na indústria também possui custo de ajustamento elevado. Neste setor o parâmetro possui quatro defasagens, mas somente três significante, indicando uma alta persistência no tempo: $\mu=\mu_{1}+\mu_{3}+\mu_{4}=0,66$.

A elasticidade cruzada do capital humano qualificado é significante a 10\%, $l H_{2 q i n, t}=-0,09 e 0,014$. O sinal negativo indica que ocorre um efeito substituição, por exemplo um aumento na demanda por capital humano qualificado de $10 \%$ leva a uma redução na demanda por capital humano menos qualificado entre $0,9 \%$ e 1,4\%. O interessante é que esta substituição não está associado a salários do capital humano qualificado, uma vez que o coeficiente $l w_{2 q i n d, t}$ não é significante. 
TABELA 3 - SETORES TRADICIONAIS - CAPITAL HUMANO MENOS QUALIFICADO

\begin{tabular}{|c|c|c|c|c|c|c|}
\hline & \multicolumn{2}{|c|}{ Comércio } & \multicolumn{2}{|c|}{ Indústria } & \multicolumn{2}{|c|}{ Serviços } \\
\hline & \begin{tabular}{|c|} 
(1) \\
$l H_{1 \text { mqcom }, t}$
\end{tabular} & $\begin{array}{c}\text { (2) } \\
l H_{1 \text { mqcom }, t}\end{array}$ & $\begin{array}{c}(3) \\
l H_{1 m q i n d, t}\end{array}$ & $\begin{array}{c}\text { (4) } \\
l H_{1 \text { mqind, }}\end{array}$ & $\begin{array}{c}\text { (5) } \\
l H_{1 \text { mqser }, t}\end{array}$ & $\begin{array}{c}\text { (6) } \\
l H_{1 m q s e r v, t}\end{array}$ \\
\hline$L . l H_{1 m q i, t}$ & $\begin{array}{c}0.433^{* * * *} \\
{[3.17]}\end{array}$ & $\begin{array}{c}0.467^{* * * *} \\
{[4.23]}\end{array}$ & $\begin{array}{c}0.552^{* * *} \\
{[4.49]}\end{array}$ & $\begin{array}{c}0.677^{* * *} \\
{[7.56]}\end{array}$ & $\begin{array}{c}0.519^{* * *} \\
{[6.41]}\end{array}$ & $\begin{array}{c}0.564^{* * *} \\
{[23.22]}\end{array}$ \\
\hline$L 2 . l H_{1 m q i, t}$ & $\begin{array}{c}0.0183 \\
{[0.15]}\end{array}$ & $\begin{array}{l}0.0459 \\
{[0.63]}\end{array}$ & $\begin{array}{l}0.234 \\
{[1.34]}\end{array}$ & $\begin{array}{c}0.279^{* *} \\
{[2.10]}\end{array}$ & $\begin{array}{c}0.387^{* * *} \\
{[3.96]}\end{array}$ & $\begin{array}{c}0.354^{* * *} \\
{[14.63]}\end{array}$ \\
\hline$L 3 . l H_{1 m q i, t}$ & $\begin{array}{c}0.332^{* * * *} \\
{[4.16]}\end{array}$ & $\begin{array}{c}0.323^{* * * *} \\
{[3.18]}\end{array}$ & $\begin{array}{c}0.306^{* *} \\
{[2.36]}\end{array}$ & $\begin{array}{c}0.289^{* *} \\
{[2.45]}\end{array}$ & & \\
\hline$L 4 . l H_{1 m q i, t}$ & & & $\begin{array}{c}-0.196^{*} \\
{[-1.67]}\end{array}$ & $\begin{array}{c}-0.216^{* * *} \\
{[-3.12]}\end{array}$ & & \\
\hline$l w_{1 q m c o m, t}$ & $\begin{array}{c}-0.101 \\
{[-0.66]}\end{array}$ & $\begin{array}{c}-0.0441 \\
{[-0.41]}\end{array}$ & & & & \\
\hline$l w_{1 m q i n d, t}$ & & & $\begin{array}{c}-0.0421 \\
{[-0.25]}\end{array}$ & $\begin{array}{l}0.210 \\
{[1.11]}\end{array}$ & & \\
\hline$l w_{1 m q s e r v, t}$ & & & & & $\begin{array}{c}-0.00109 \\
{[-0.02]}\end{array}$ & $\begin{array}{c}-0.0124 \\
{[-0.60]}\end{array}$ \\
\hline$l y_{\text {pibcom }, t}$ & $\begin{array}{l}0.189 \\
{[1.41]}\end{array}$ & $\begin{array}{l}0.130 \\
{[1.29]}\end{array}$ & $\begin{array}{l}0.150 \\
{[0.91]}\end{array}$ & $\begin{array}{l}0.0281 \\
{[0.27]}\end{array}$ & & \\
\hline$l y_{\text {pibind }, t}$ & $\begin{array}{c}-0.0156 \\
{[-0.25]}\end{array}$ & $\begin{array}{c}-0.0871 \\
{[-1.29]}\end{array}$ & $\begin{array}{c}0.0768 \\
{[0.96]}\end{array}$ & $\begin{array}{c}0.0772 \\
{[1.36]}\end{array}$ & & \\
\hline$l y_{\text {pibserv, } t}$ & $\begin{array}{c}-0.0240 \\
{[-0.29]}\end{array}$ & $\begin{array}{c}0.0247 \\
{[0.21]}\end{array}$ & $\begin{array}{c}-0.0674 \\
{[-0.54]}\end{array}$ & $\begin{array}{l}-0.0131 \\
{[-0.09]}\end{array}$ & & \\
\hline$l w_{2 q c o m, t}$ & $\begin{array}{c}0.0245 \\
{[0.75]}\end{array}$ & $\begin{array}{l}0.0116 \\
{[0.65]}\end{array}$ & & & & \\
\hline$l H_{2 q c o m, t}$ & $\begin{array}{l}0.0433 \\
{[0.89]}\end{array}$ & $\begin{array}{c}0.0756^{* * *} \\
{[2.11]}\end{array}$ & & & & \\
\hline$l w_{2 q i n d, t}$ & & & $\begin{array}{c}-0.0255 \\
{[-0.58]}\end{array}$ & $\begin{array}{c}-0.0230 \\
{[-0.71]}\end{array}$ & & \\
\hline$l H_{2 q i n d, t}$ & & & $\begin{array}{c}-0.0940^{*} \\
{[-1.84]}\end{array}$ & $\begin{array}{c}-0.141^{* * *} \\
{[-3.70]}\end{array}$ & & \\
\hline$l w_{2 q s e r v, t}$ & & & & & $\begin{array}{c}-0.1240 \\
{[-0.60]}\end{array}$ & $\begin{array}{c}-0.0010 \\
{[-0.02]}\end{array}$ \\
\hline$l H_{2 q s e r v, t}$ & & & & & $\begin{array}{c}0.0690 \\
{[1.51]} \\
\end{array}$ & $\begin{array}{c}0.0648^{* * *} \\
{[5.56]} \\
\end{array}$ \\
\hline
\end{tabular}

$t$ statistics in brackets

${ }^{*} \mathrm{p}<0.10,{ }^{* *} \mathrm{p}<0.05,{ }^{* * *} \mathrm{p}<0.01$ 
TABELA 3 - SETORES TRADICIONAIS - CAPITAL HUMANO MENOS QUALIFICADO. (CONTINUAÇÃO)

\begin{tabular}{l|c|c|c|c|c|c}
\hline & \multicolumn{2}{|c|}{ Comércio } & \multicolumn{2}{c|}{ Indústria } & \multicolumn{2}{c}{ Serviços } \\
\cline { 2 - 7 } & $(1)$ & $(2)$ & $(3)$ & $(4)$ & $(5)$ & $(6)$ \\
& $l H_{1 m q c o m, t}$ & $l H_{1 m q c o m, t}$ & $l H_{1 \text { mqind }, t}$ & $l H_{1 \text { mqind }, t}$ & $l H_{1 \text { mqserv }, t}$ & $l H_{1 \text { mqserv }, t}$ \\
\hline Constante & 0.550 & 0.467 & 0.351 & -1.441 & 0.505 & $0.477^{* * *}$ \\
& {$[0.75]$} & {$[0.63]$} & {$[0.44]$} & {$[-0.94]$} & {$[1.16]$} & {$[3.17]$} \\
Observações & 216 & 216 & 216 & 216 & 216 & 216 \\
AR(1) & 0,003 & 0,000 & 0,001 & 0,007 & 0,000 & 0,005 \\
AR(2) & 0,969 & 0,736 & 0,868 & 0,891 & 0,317 & 0,429 \\
Sargan teste & - & 0,954 & - & 0,987 & - & 0,943 \\
\hline
\end{tabular}

$t$ statistics in brackets

${ }^{*} \mathrm{p}<0.10,{ }^{* *} \mathrm{p}<0.05,{ }^{* *} \mathrm{p}<0.01$

No setor de serviços, a demanda por capital humano menos qualificado depende quase que exclusivamente da quantidade empregada no período anterior $\left(l H_{1 q i t}=0,90 l H_{1 t-1}\right)$. Este setor possui o coeficiente de ajustamento intertemporal mais elevado dos setores analisados, sendo o seu valor de $\mu=\mu_{1}+\mu_{2}=0,90$. Como este coeficiente representa o custo de ajustamento no tempo, o setor de serviços é o que mais recebe impacto de políticas que afetam os custos de contratações de capital humano menos qualificado.

Em suma, nos setores tradicionais o custo de ajustamento é mais elevado para o capital humano menos qualificado, especialmente no setor de serviços. Estes resultados indicam a necessidade de se aumentar a oferta de pessoas com qualificação em nível de segundo grau para estes setores. Considerando que este parâmetro mede também os custos associados a legislação trabalhista em comparação com a produtividade deste tipo de capital humano, se faz necessário rever esta política urgente para este tipo de capital.

\subsection{Setores de Alta Tecnologia}

\subsubsection{Capital Humano Qualificado}

A indústria de alta tecnologia possui comportamento diferente dos setores tradicionais. O seu custo de ajustamento em torno de $\lambda=\lambda_{2}=0,20$ é bastante baixo, sendo que as elasticidades cruzadas de salários e do produto não são significantes. Diferentemente dos demais setores, a elasticidade cruzada do capital humano menos qualificado é significante, $l H_{2 \text { miat }, t}=0,424 e 0,437$. Este resultado indica que o capital humano menos qualificado é complementar ao capital humano qualificado e depende deste último sua demanda, mais 
do que isso, este setor parece usar uma proporção fixa entre estes capitais humanos. Por exemplo, um aumento de $10 \%$ na contratação de capital humano menos qualificado leva a um aumento na demanda de capital humano qualificado entre $4,2 \%$ e $4,3 \%$.

Tabela 4 - Indústria e Serviço de Alta Tecnologia - Capital Humano Qualificado

\begin{tabular}{|c|c|c|c|c|}
\hline & \multicolumn{2}{|c|}{$\begin{array}{l}\text { Indústria de Alta Tecnolo- } \\
\text { gia (IAT) }\end{array}$} & \multicolumn{2}{|c|}{$\begin{array}{c}\text { Serviço de Alta Tecnologia } \\
(\mathrm{SAT})\end{array}$} \\
\hline & $\begin{array}{c}\text { (1) } \\
l H_{1 \text { qiat }, t}\end{array}$ & $\begin{array}{c}\text { (2) } \\
l H_{1 \text { qiat }, t}\end{array}$ & $\begin{array}{c}\text { (3) } \\
l H_{1 q s a t, t}\end{array}$ & $\begin{array}{c}\text { (4) } \\
l H_{1 q s a t, t}\end{array}$ \\
\hline$L . l H_{1 q i, t}$ & $\begin{array}{l}0.0547 \\
{[0.48]}\end{array}$ & $\begin{array}{l}0.106^{* *} \\
{[2.12]}\end{array}$ & $\begin{array}{c}0.280^{* *} \\
{[2.01]}\end{array}$ & $\begin{array}{c}0.315^{* * *} \\
{[4.15]}\end{array}$ \\
\hline$L 2 . l H_{1 q i, t}$ & $\begin{array}{l}0.205^{*} \\
{[1.86]}\end{array}$ & $\begin{array}{l}0.154^{* *} \\
{[2.56]}\end{array}$ & $\begin{array}{l}0.222^{* *} \\
{[2.00]}\end{array}$ & $\begin{array}{c}0.206^{* * *} \\
{[3.40]}\end{array}$ \\
\hline$L 3 . l H_{1 q i, t}$ & $\begin{array}{l}0.0241 \\
{[0.34]}\end{array}$ & $\begin{array}{c}-0.0132 \\
{[-0.21]}\end{array}$ & $\begin{array}{c}0.301 * * * \\
{[3.19]}\end{array}$ & $\begin{array}{c}0.320^{* *} \\
{[2.33]}\end{array}$ \\
\hline$l w_{1 q i a t, t}$ & $\begin{array}{c}0.213 \\
{[1.04]}\end{array}$ & $\begin{array}{l}0.220 \\
{[1.10]}\end{array}$ & $\begin{array}{c}-0.0102 \\
{[-0.36]}\end{array}$ & $\begin{array}{c}-0.00579 \\
{[-0.38]}\end{array}$ \\
\hline$l y_{q p i b, t}$ & $\begin{array}{l}0.549 \\
{[1.64]}\end{array}$ & $\begin{array}{l}0.556 \\
{[1.51]}\end{array}$ & $\begin{array}{l}0.151 \\
{[1.51]}\end{array}$ & $\begin{array}{c}0.128 * \\
{[1.81]}\end{array}$ \\
\hline$l w_{1 q s a t, t}$ & $\begin{array}{l}-0.102 \\
{[-0.32]}\end{array}$ & $\begin{array}{c}-0.0670 \\
{[-0.19]}\end{array}$ & $\begin{array}{l}-0.122 \\
{[-0.96]}\end{array}$ & $\begin{array}{c}-0.0940 \\
{[-1.10]}\end{array}$ \\
\hline$l w_{2 m q i a t, t}$ & $\begin{array}{l}0.186 \\
{[1.01]}\end{array}$ & $\begin{array}{c}0.0282 \\
{[0.12]}\end{array}$ & $\begin{array}{l}-0.0102 \\
{[-0.36]}\end{array}$ & $\begin{array}{c}-0.00579 \\
{[-0.38]}\end{array}$ \\
\hline$l w_{2 m q s a t, t}$ & & & $\begin{array}{c}0.0208 \\
{[0.50]}\end{array}$ & $\begin{array}{c}0.0212 \\
{[1.56]}\end{array}$ \\
\hline$l H_{2 m q i a t, t}$ & $\begin{array}{c}0.424^{* *} \\
{[2.45]}\end{array}$ & $\begin{array}{c}0.437^{* * *} \\
{[5.44]}\end{array}$ & & \\
\hline$l H_{2 m q s a t, t}$ & & & $\begin{array}{c}-0.0160 \\
{[-0.12]}\end{array}$ & $\begin{array}{c}-0.0311 \\
{[-0.76]}\end{array}$ \\
\hline Constante & $\begin{array}{c}-9.703^{* * *} \\
{[-2.16]}\end{array}$ & $\begin{array}{l}-8.966 \\
{[-1.38]}\end{array}$ & $\begin{array}{c}0.827 \\
{[0.82]}\end{array}$ & $\begin{array}{l}0.718 \\
{[1.36]}\end{array}$ \\
\hline Dummies anos & Sim & Sim & Sim & Sim \\
\hline Observações & 216 & 216 & 216 & 216 \\
\hline $\mathrm{AR}(1)$ & 0.014 & 0.029 & 0.021 & 0.087 \\
\hline $\operatorname{AR}(2)$ & 0.536 & 0.603 & 0.428 & 0.761 \\
\hline Sargan teste & - & 0.999 & - & 0.991 \\
\hline
\end{tabular}

Estatística t entre parenteses

Valores das significâncias: ${ }^{*} \mathrm{p}<0.10,{ }^{* *} \mathrm{p}<0.05,{ }^{* *} \mathrm{p}<0.01$ 
O setor de serviços de alta tecnologia também possui comportamento diferente dos demais. Neste setor o fator preponderante é a variável custo de ajustamento, $\lambda=\lambda_{1}+\lambda_{2}+\lambda_{3}=0,80$, que é bastante elevado. Neste setor a dependência é quase que exlcusivamente da quantidade empregada no período anterior, ou seja, $l H_{1 q i t}=0,80 l H_{1 t-1}$, uma vez que as elasticidades do produto e dos salários e as cruzadas não lograram ser significantes. O crescimento do emprego de pessoas menos qualificadas neste setor não converge para um nível ótimo de emprego no longo prazo. A percepção é de que o mesmo sofre de algum tipo de restrição ou associada a custos ou a falta de oferta. Fizemos dois testes adicionais: 1) primeiro foi a inclusão do PIB dos demais setores, que não resultou em significância; 2) segundo foi considerado os salários dos demais setores da economia, que também não resultou em significância.

Considerando os resultados das regressões dos dois testes, em especial o fato de que os salários não lograram serem significantes, estes eliminam o problema de oferta que requer melhores salários para ser contratado neste setor. Sendo que o coeficiente do custo de ajustamento está associado a custo de contratações e demissões, conforme o modelo, a conclusão é que este setor sofre com políticas econômicas que afetam os custos de demissões e contratações de capital humano qualificado. Este é um resultado esperado, segundo Hamermesh e Pfann (1996), pois os custos de capital humano qualificado podem chegar ao equivalente a um ano de salários.

\subsubsection{Capital Humano Menos Qualificado}

De acordo com as estimativas da coluna (1) e (2) da Tabela 5 a seguir, a indústria de alta tecnologia possui também um alto custo de ajustamento $\mu=\mu_{1}+\mu_{2}=0,69$. Apesar deste efeito negativo, este setor sofre o impacto positivo da contratação de capital humano qualificado. A elasticidade cruzada de demanda por capital humano qualificado $l H_{2 q i a t, t}=0,292$ é positiva e indica que aumentos na demanda por capital humano qualificado em 10\% leva a um aumento na demanda por capital humano menos qualificado de 2,92\%. Este resultado confirma o anterior de que os capitais humanos qualificado e menos qualificado são complementares na indústria de alta tecnologia. Contratação de um tipo de capital humano leva a contratação do outro. As demais elasticidades não foram significantes.

O setor de serviços de alta tecnologia possui um comportamento bastante diferente dos demais com relação a contratação de capital humano menos qualificado. Primeiro, como esperado este setor possui um alto custo de ajustamento com os coeficientes dos períodos significantes equivalente a $\mu=\mu_{1}+\mu_{2}=0,71$, portanto próximo do obtido na indústria de alta tecnologia. Segundo, os salários da indústria de alta tecnologia são importantes na determinação da demanda por capital humano menos qualificado 
por este setor, pois $l w_{1 \text { mqiat } t}=-0,146 e-0,209$. Terceiro, os salários do capital humano qualificado empregado no setor de serviços de alta tecnologia $l w_{2 q s a t, t}=-0,187 e-0,162$ também exercem impacto negativo. Aumentos de salários reais no setor de alta tecnologia para pessoas menos qualificadas e qualificadas leva a uma redução no emprego de capital humano menos qualificado no setor de serviços de alta tecnologia.

TABELA 5 - ALTA TECNOLOGIA - CAPITAL HUMANO MENOS QUALIFICADO

\begin{tabular}{|c|c|c|c|c|}
\hline & \multicolumn{2}{|c|}{ Indústria de Alta Tecnologia } & \multicolumn{2}{|c|}{ Serviços de Alta Tecnologia } \\
\hline & $\begin{array}{c}\text { (1) } \\
l H_{1 \text { mqiat } t}\end{array}$ & $\begin{array}{c}\text { (2) } \\
l H_{1 \text { mqiat } t}\end{array}$ & $\begin{array}{c}\text { (3) } \\
l H_{1 m q s a t, t}\end{array}$ & $\begin{array}{c}(4) \\
l H_{1 m q s a t, t}\end{array}$ \\
\hline$L . l H_{1 m q i, t}$ & $\begin{array}{c}0.463^{* * *} \\
{[6.66]}\end{array}$ & $\begin{array}{c}0.378 * * * \\
{[6.67]}\end{array}$ & $\begin{array}{c}0.368 * * * \\
{[4.11]}\end{array}$ & $\begin{array}{c}0.325^{* * *} \\
{[4.16]}\end{array}$ \\
\hline$L 2 . l H_{1 m q i, t}$ & $\begin{array}{c}0.230^{* * *} \\
{[2.97]}\end{array}$ & $\begin{array}{c}0.298 * * * \\
{[6.67]}\end{array}$ & $\begin{array}{c}0.325^{* * *} \\
{[2.81]}\end{array}$ & $\begin{array}{c}0.377^{* * * *} \\
{[3.76]}\end{array}$ \\
\hline$L 3 . l H_{1 m q i, t}$ & & & $\begin{array}{l}0.0107 \\
{[0.10]}\end{array}$ & $\begin{array}{c}-0.0459 \\
{[-0.43]}\end{array}$ \\
\hline$l w_{1 m q i a t, t}$ & $\begin{array}{c}-0.0340 \\
{[-0.15]}\end{array}$ & $\begin{array}{c}-0.276^{*} \\
{[-1.91]}\end{array}$ & $\begin{array}{c}-0.146^{* * *} \\
{[-3.89]}\end{array}$ & $\begin{array}{c}-0.209^{* * *} \\
{[-5.98]}\end{array}$ \\
\hline$l y_{m q p i b, t}$ & $\begin{array}{l}0.0174 \\
{[0.09]}\end{array}$ & $\begin{array}{c}0.0946 \\
{[1.30]}\end{array}$ & $\begin{array}{l}0.143 \\
{[1.14]}\end{array}$ & $\begin{array}{c}0.233^{* *} \\
{[2.05]}\end{array}$ \\
\hline$l w_{2 q i a t, t}$ & $\begin{array}{c}0.0525 \\
{[0.56]}\end{array}$ & $\begin{array}{c}0.120^{* * *} \\
{[2.63]}\end{array}$ & & \\
\hline$l H_{2 q i a t, t}$ & $\begin{array}{c}0.292^{* * *} \\
{[3.41]}\end{array}$ & $\begin{array}{c}0.235^{* * *} \\
{[4.51]}\end{array}$ & & \\
\hline$l w_{2 q s a t, t}$ & & & $\begin{array}{c}-0.187^{*} \\
{[-1.69]}\end{array}$ & $\begin{array}{c}-0.162^{* * *} \\
{[-2.92]}\end{array}$ \\
\hline$l H_{2 q s a t, t}$ & & & $\begin{array}{c}0.101 \\
{[0.79]}\end{array}$ & $\begin{array}{c}0.0854 \\
{[1.03]}\end{array}$ \\
\hline Constante & $\begin{array}{c}0.125 \\
{[0.05]}\end{array}$ & $\begin{array}{c}0.452 \\
{[0.45]}\end{array}$ & $\begin{array}{c}2.065^{*} \\
{[1.91]}\end{array}$ & $\begin{array}{l}1.501^{*} \\
{[1.89]}\end{array}$ \\
\hline Observações & 216 & 216 & 216 & 216 \\
\hline $\operatorname{AR}(1)$ & 0,001 & 0,013 & 0,001 & 0,004 \\
\hline $\operatorname{AR}(2)$ & 0,323 & 0,807 & 0,953 & 0,620 \\
\hline Sargan teste & - & 0,998 & - & 0,999 \\
\hline
\end{tabular}

Estatistica $t$ entre parenteses

Valores da significância: ${ }^{*} \mathrm{p}<0.10,{ }^{* *} \mathrm{p}<0.05,{ }^{* * *} \mathrm{p}<0.01$ 
Os resultados acima indicam que a contratação de capital humano menos qualificado está vinculado aos salários prevalentes na indústria de alta tecnologia, portanto, existe uma associação no processo de contratação entre estes setores. Outro aspecto interessante é que aumentos salariais reais neste setor do capital humano qualificado leva a uma redução de demanda. A explicação é que estes capitais são complementares neste setor e aumentos de salários levam a uma redução de capital humano qualificado e menos qualificado também.

No setor de alta tecnologia as elasticidades de demanda de longo prazo podem ser calculadas devido a significância do custo de ajustamento. Por exemplo, a elasticidade cruzada da demanda por capital humano qualificado é a seguinte na indústria de alta tecnologia $\delta=\frac{t_{2} \text { zitat }}{1-\lambda}=\frac{0,292}{1-0,69}=0,94$. Empregando a mesma fórmula para o setor de serviços de alta tecnologia podemos obter duas elasticidades de longo prazo, as elasticidades cruzada dos salários da indústria que equivale $\omega=-0,50$ e a do capital humano qualificado $\kappa=-0,64$. Ambas indicam uma maior interdependência no longo prazo entre os salários dos setores de alta tecnologia e a contratação de capitais humanos menos qualificados nesse setor.

Em suma, no setor de alta tecnologia a indústria possui um custo de ajustamento superior para o capital humano menos qualificado. Enquanto que no setor de serviços de alta tecnologia temos que o custo de ajustamento é maior para o capital humano qualificado. Estes resultados sinalizam a necessidade de aumentar os cursos de qualificação em nível de segundo grau voltados para a indústria tecnológica e em nível superior para o setor de serviços de alta tecnologia.

\section{Considerações finais}

O modelo de Sargent (1978) permitiu estimarmos as demandas de curto e longo prazo dos capitais humanos qualificados e menos qualificados. O principal resultado é de que os custos de ajustamento do capital humano menos qualificado é bastante elevado e superior ao do capital humano qualificado nos setores tradicionais (comércio, indústria e serviços). Este resultado indica que a preferência destes setores é por capital humano menos qualificado. E, portanto, estariam encontrando mais restrição na contratação dos mesmos do que de capital humano qualificado.

A demanda por capital humano menos qualificado, no entanto, está associado quase que exclusivamente a custos de contratação, custos estes superiores aos do capital humano qualificado. A percepção é de que a necessidade de investimento em treinamento e os custos associados a demissões e contratações desse tipo de capital humano levam as empresas dos estados a manterem os contratados e evitarem novas contratações. 
Outro aspecto que faz com que o custo de contratação do capital humano qualificado seja inferior nestes setores está associado ao seu maior crescimento. Provavelmente este crescimento tenha influenciado os níveis salariais de tal maneira a serem mais atrativos e, portanto, a sua contratação passou a depender mais do crescimento do produto do que de salários e ou de outros custos associados, como investimento em treinamento, políticas salarias diferenciadas, etc. No caso do setor de serviços esta elasticidade do produto é superior a um, portanto elástica.

Nos setores de alta tecnologia temos que para a indústria de alta tecnologia a contratação de capital humano menos qualificado também possui um custo maior que o capital humano qualificado. O interessante é que a contratação de capital humano qualificado também depende da contratação de pessoas menos qualificado, uma vez que a elasticidade cruzada entre ambos é positiva. O mesmo ocorre na demanda por capital humano menos qualificado onde a elasticidade do capital humano qualificado também é positiva. Este resultado confirma a complementariedade entre estes capitais na indústria de alta tecnologia, assim nesse setor sempre há a necessidade de contratação proporcional entre os mesmos.

O setor de serviços de alta tecnologia é o único onde o custo de contratação de capital humano qualificado é superior ao menos qualificado. Neste setor a contratação de pessoas qualificadas não depende de salários prevalentes no setor ou nos demais setores da economia. Os testes adicionais indicaram que o ajustamento lento no tempo parece estar associado exclusivamente a outros custos que não sejam salariais. Já o capital humano menos qualificado é altamente dependente do salário real do mesmo capital humano na indústria de alta tecnologia e do salário real do capital humano qualificado empregado nesse mesmo setor. Aumento desses salários reais reduzem a demanda por capital humano menos qualificado.

Em suma, os resultados indicam que é mais dispendioso para os setores em geral a contratação de pessoas com até 11 anos de escolaridade, exceto para o setor de serviços de alta tecnologia cujo maior custo é o de contratação de pessoas com acima de 11 anos de educação. Assim, a necessidade de qualificação de pessoas com 11 anos ou menos de escolaridade para estes setores e pessoas com educação em nível superior para o setor de serviços de alta tecnologia é a política mais adequada a ser seguida. Este resultado geral indica que o Brasil difere dos países mais avançados onde o custo de contratação de pessoas qualificadas é maior em função da grande oferta de pessoas com escolaridade de segundo grau. 


\section{Referências Bibliográficas}

ARBACHE, J. S.; CORSEUIL, C. H. (2004). "Liberalização Comercial e Estruturas de Emprego e Salário.” Revista Brasileira de Economia, v.58(4), pp. 485-505.

ARELLANO, M.; BOND, S. R. (1991). "Some Tests of Specification for Panel Data: Monte Carlo Evidence and an Application to Employment Equations." Review of Economic Studies, n. 58, pp. 277-297.

ARELLANO, M.; BOVER, O. (1995). "Another Look at the Instrumental Variable Estimation of Error-Components Models.” Journal of Econometrics, n. 68, pp. 29-51.

BALTAGI, B. H.; LI, Q. (1991). "A transformation that will circumvent the problem of autocorrelation in an error-component model." Journal of Econometrics, v. 48 (3), pp. 385-393.

BALTAGI, B. H.; LI, Q. (1995). “Testing AR(1) against MA(1) disturbances in an error component model." Journal of Econometrics, v. 68 (1), pp. 133-151.

BARROS, R. P.; CORSEUIL, C. H. (2004). “The Impact of Regulations on Brazilian Labor Market Performance." In: Law and Employment: Lessons From Latin America and the Caribbean. Eds. James J. Heckman e Carmen Pagés. Chicago: University of Chicago Press.

BLUNDELL, R.; BOND, S. (1997). "Initial Conditions and Moment Restrictions in Dynamic Panel Data Models." University College London Discussion Paper, pp. 97-07.

BLUNDELL, R.; BOND, S. (1998). "Initial conditions and moment restrictions in dynamic panel data models.” Journal of Econometrics, v. 87 (1), pp. 115-143.

BREUSH, T. S.; PAGAN, A. R. (1980). "The Lagrange multiplier test and its applications to model specification in econometrics." Review of Economic Studies, v.47, pp. 239-253.

CHAHAD, J. P.; LUQUE, R. (1989). "Elasticidade emprego-produto no ciclo industrial brasileiro.” In: SEDLACECK, G.; BARROS, R. P. (Org.). Mercado de trabalho e distribuição de renda: uma coletânea. IPEA, Série Monográfica 35.

DIAS, J. (2012). "Restrição de Oferta e Demanda por Capital Humano Qualificado e o Crescimento Econômico e das Exportações dos Estados Brasileiros." Working Paper n. 30, BNDES/ANPEC.

DIAS, J. (2014). "Restrição de Oferta e Demanda por Capital Humano Qualificado e o Crescimento Econômico e das Exportações dos Estados Brasileiros.” Prelo: Revista Economia, ANPEC, RJ.

DIAS, J; DIAS, M. H. A. A (2011). "Demanda por Capital Humano Qualificado no Brasil: O Efeito da Estrutura Econômica e Social.” Texto para Discussão PCE.

FERNANDES, R.; MENEZES FILHO, N. A . (2002). "Escolaridade e demanda relativa por trabalho: uma avaliação para o Brasil nas décadas de 80 e 90.” In: CHAHAD, Z. P. D.; MENEZES-FILHO, A. N. (Org.). Mercado de Trabalho no Brasil: salário, emprego e desemprego numa era de grandes mudanças. São Paulo: LTR, v. 1, pp. 199-221.

GIOVANETTI, B.; MENEZES-FILHO, N. (2006). "Trade liberalization and the demand for skilled labour in Brazil.” Economia (Journal of LACEA), v.7 (1). 
GONZAGA, G.; CORSEUIL, C. H. (2001). "Emprego industrial no Brasil: análise de curto e longo prazos.” Revista Brasileira de Economia, v. 55 (4), pp. 467-491.

GREENE, W.H. (2000). "Models with discrete dependent variables”. In: GREENE, W. H. (Ed.). Econometric Analysis, 3ed. Prentice-Hall International, England Cliff, NJ.

HAMERMESH, D. S. (1989). "Labor Demand and Structure of Adjustment Costs." The American Economic Review, v.79 (4).

HAMERMESH, D. S. (2004). "Labor Demand in Latin America and the Caribbean: what does it tell us?” In: HECKMAN, J. J.; PAGÉS, C. (Eds.). Law and Employment: Lessons From Latin America and the Caribbean. Chicago: University of Chicago Press.

HAMERMESH, D. S.; PFANN, G. A. (1996). “Adjustment Costs in Factor Demand.” Journal of Economic Literature, v. 34 (3), pp. 1264-1292.

HAUSMAN, J. A. (1978). "Specification tests in econometrics." Econometrica, v. 46 (6), pp. 1251-1271.

HSIAO, C. (1982). "Autoregressive Modeling and Casual Ordering of Econometric Variables.” Journal of Economic Dynamics and Control, v. 4, pp. 243-259.

IBGE. (2009). Pesquisa Nacional por Amostra de Domicílios 2009. PNAD, v. 30, Rio de Janeiro: IBGE, 2009.

IPEADATA. URL [on-line]: <http://www.ipeadata.gov.br>.

MEYER, J. (1998). Custo de ajustamento e a demanda por trabalho no Brasil: uma estimativa setorial. Rio de Janeiro: PUC/Departamento de Economia (Dissertação de Mestrado).

MENEZES-FILHO, N. A.; RODRIGUES JR., M. (2003). "Tecnologia e demanda por qualificação na indústria brasileira.” Revista Brasileira de Economia, v. 57 (3), pp. 569-603.

PEREIRA, P. V.; CICHELLI, R.; BARROS, R. P. (1989). “Absorção de mão-de-obra na indústria de transformação.” In: SEDLACECK, G.; BARROS, R. P. (Org.). Mercado de trabalho e distribuição de renda: uma coletânea. IPEA, Série Monográfica 35 .

PEREIRA, P. V; GONZAGA, G. (1998). “A divisão do Trabalho e a Demanda Dinâmica por Emprego e Horas.” Texto para Discussão, n. 615, IPEA.

RIBEIRO, E. P; JACINTO, P. A. (2008). Estimando a Demanda por Trabalhadores Qualificados no Brasil 1997-2003. URL [on-line]: bibliotecadigital.fgv.br/ocs/ index.php/sbe/EBEo8/paper/download/440/72.

SARGAN, J. D. (1988). "Testing for Misspecification after Estimating Using Instrumental Variables." In: MAASOUMI, E. (Ed.). Contributions to Econometrics. Cambrige: Cambrige University Press.

SARGENT, T. J. (1978). "Estimation of Dynamic Labor Demand Schedules Under Rational Expectations.” Journal of Political Economy, v. 86(6).

WINDMEIJER, F. (2005). "A finite sample correction for the variance of linear e eficient two-step GMM estimators.” Journal of Econometrics, v. 126, pp. 25-51.

WOOLDRIDGE, J. (2002). Econometric analysis of cross-section and panel data. 
DIAS, J. Desafios da Qualificação no Brasil: Demanda dos Setores Tradicionais......

Cambridge: MIT Press.

Recebido em: 15/03/2014 Aceito em: 16/o6/2014 
